\title{
EVALUATION OF WAVE RUN-UP PREDICTIONS FROM PARAMETRIC MODELS ON TRINIDAD BEACHES
}

\author{
Shani Brathwaite ${ }^{1 *}$, Deborah Villarroel-Lamb ${ }^{2}$ \\ ${ }^{1,2}$ Faculty of Engineering, The University of the West Indies, Trinidad \\ ${ }^{1}$ Email: Shani.Brathwaite@sta.uwi.edu *(Corresponding author) \\ ${ }^{2}$ Email: Deborah.Villarroel-Lamb@sta.uwi.edu
}

\begin{abstract}
The comprehension of wave run-up is essential to coastal engineering. It is required to obtain an understanding of beach profile changes, beach recovery and the interaction of waves on coastal structures. Several empirical expressions have been defined to predict extreme wave run-up positions through the comparisons of offshore wave parameters, beach slopes and synchronous run-up observations. This paper assesses the accuracy of wave run-up formulae on three Trinidad beaches. Run-up data were collected using Traditional Surveying Techniques and statistically analysed to determine both the maximum run-up and the $2 \%$ run-up exceedance. Observed values of wave run-up were compared to values predicted by four (4) field wave run-up models. All models were found to inadequately predict run-up observations with an occurrence of predominantly overestimations. Stockdon et al. [1] provided the best estimation of run-observation with root mean square error and scatter index of 0.15 .
\end{abstract}

Keywords: Swash infiltration, Swash zone, Wave run-up.

https://doi.org/10.47412/YLGY1367

\subsection{Introduction}

Wave run-up is defined as the time-varying position of the landward extent of the water's edge, measured vertically from the mean water level position [2, 3]. It results from the combination of two dynamically different components: a super elevation of the mean water level, setup, and timevarying fluctuations about that mean, swash [3].

The energy delivered by run-up motion is greatly responsible for sediment transport in the swash zone and ultimately dune and beach erosion. The prediction of wave run-up is critical for the efficient design and maintenance of coastal structures as it is used to estimate the percentage of overtopping waves as well as run-up flow depths and velocities $[4,5,6]$. Other applications such as coastal flood mapping, beach nourishment and set back criteria also rely on wave run-up estimations. Consequently, the accurate prediction of maximum wave run-up is of critical importance to coastal engineers and planners [7].

Many models have been developed using parameters that are relatively easy to measure such as offshore wave height (Ho), wave length (L), wave period (T), and beach slope ( $\tan \beta)$. Through the knowledge of these parameters and their relationships, run-up models have been designed 
using both field and laboratory data. However, laboratory designed models may have some limitations when applied to natural beaches and field designed models are often not applicable to a wide range of beaches. Research by Di Luccio et al. [8] and Silva et al. [9] found inadequate estimations of wave run-up using models derived using natural beaches. The poor agreement between run-up predictions and observations has been attributed to differences in data collection techniques and environmental conditions of the study areas. This paper aims to assess the accuracy of four (4) empirical formulae to predict maximum run-up on Trinidad beaches.

\section{Existing run-up models}

The earliest formulation of wave run-up by Hunt in 1959 [10], was based on laboratory experiments of monochromatic waves on smooth impermeable beaches with slopes less than 1:10. A simple model, it identifies a distinct relationship between the vertical extent of run-up and the surf similarity parameter expressed in equation 1.

$$
\frac{R_{\max }}{H}=K \xi
$$

Where $R_{\max }$ is the maximum vertical wave run-up from the SWL, $H$ is wave height (assumed to be deep water wave height $H_{o}$ ), $K$ is an empirical constant and $\xi$ is the surf similarity parameter.

Using concepts by Miche [11] on monochromatic waves, Hunt [10] expressed that the amount of energy reflected on the beach slope is highly dependent on the steepness of the wave that is propagated [4]. For surging conditions, most of the energy is reflected onto the beach slope, as little to no energy is dissipated as it approaches the foreshore. However, in the case of breaking waves, much energy is dissipated as it propagates across the surf zone. Hunt's formula was found to over predict wave run-up on beaches for irregular waves when the beach face slope was used and under predict when the surf zone slope was used. As a result, a weighted average of both surf zone and beach face slope was suggested [12].

Several other expressions were later defined to predict wave run-up, including one set out by Holman in 1986 [13]. The equation for $R_{2} \%$, the run-up elevation exceeded by only $2 \%$ of swash events for a given period, is given by equation 2 .

$$
\frac{R_{2 \%}}{H_{S}}=0.83 \xi_{o}+0.2
$$

Holman [13] utilized 149 sets of 35-minute data runs, collected on reflective beach slopes (0.07 to 0.2 ), with wave periods of 6 to $16 \mathrm{~s}$ and incident wave heights between 0.4 and $4.0 \mathrm{~m}$. He discovered that significantly less scatter was observed when wave set-up was removed from the total run-up formula. His research resulted in an expression that recognizes a distinct relationship between $R_{2} \%$ non-dimensionalised by significant wave height and the Iribarren number.

Nielsen and Hanslow [12] further examined run-up distributions on a wide cross-section of natural beaches on the New South Wales coast of Australia. Using data collected data on six (6) moderately dissipative to reflective beaches with significant wave period 6.4 to $11.5 \mathrm{~s}$ they defined $R_{2} \%$ by the following equations; 


$$
R_{2 \%}=1.98 * L_{z w m}
$$

Where

$$
L_{\text {zwm }}=0.6\left(H_{\text {orms }} * L_{o}\right)^{0.5} \tan \beta \quad \text { for } \tan \beta \geq 0.1
$$

(4)

$$
L_{\text {zwm }}=0.05\left(H_{\text {orms }} * L_{o}\right)^{0.5} \quad \text { for } \tan \beta<0.1
$$

Nielsen and Hanslow [12] found that for steep beaches with slopes greater than or equal 0.1, equations by Hunt [10] and Holman [13] were a good indication of wave run-up distributions. Further to that they added that steep slopes drained quickly as they tend to have more porous and coarse grain sand. However, they discovered that for flat beaches with slopes less than 0.1, run-up distributions were independent of foreshore beach slope.

A study conducted on the dissipative beaches of Oregon, by Ruggiero [2] also proposed that the prediction of $R_{2} \%$ heavily depends on the deep water wave height. However, when combined with data collected by Holman [13], wave run-up elevations were found to be also influenced by beach slope, $\tan \beta$, and deep water wavelength, $L_{o}$. As a result, he expressed run-up elevations as having an equal dependency on slope, wave height and wavelength. His final expression of $R_{2} \%$ is given by equation 6 .

$$
R_{2 \%}=0.27\left(\tan \beta H_{o} L_{o}\right)^{0.5}
$$

However, Stockdon et al. [1] found that $R_{2} \%$ was best parameterized as a function of two dynamically different components set-up, $\langle\eta>$ and swash, $S$. Using data collected on ten (10) field experiments, covering a wide range of environmental conditions, they defined run-up for natural beaches by equation 7 .

$$
R_{2 \%}=1.1\left(0.35 \tan \beta\left(H_{O} L_{O}\right)^{0.5}+\frac{\left(H_{O} L_{O}\left(0.563 \tan \beta^{2}+0.004\right)\right)^{0.5}}{2}\right)
$$

For extremely dissipative conditions $\left(\xi_{0}<0.3\right)$, they found that the magnitude of $2 \%$ wave run-up was independent of beach slope and recommended the uses of equation 8 .

$R_{2 \%}=0.043\left(H_{o} L_{o}\right)^{0.5}$

In 2014, Villarroel-Lamb et al. [14] conducted a series of laboratory tests in a coastal flume at the University College London (UCL) London, UK to investigate the influence of bed permeability on maximum wave run-up. Four angles of beach slopes; 9, 11, 13 and 15 degrees were used along with 4 degrees of bed permeability; $0.311,0.105,0.401$ and $1 \times 10^{-8} \mathrm{~ms}^{-1}$, the latter representing an impermeable bed similar to that of clay. Only regular or monochromatic waves were manipulated in this experiment with a water depth of $400 \mathrm{~mm}$. Further details of this research were reviewed in the previous section of the document. Their research found a distinct relationship 
between maximum wave run-up and bed permeability, fitting a Hunt-type formulation as given in equation 9.

$$
\frac{R_{\max }}{H_{O}}=C_{\text {perm }}\left(\frac{\tan \beta}{\sqrt{\frac{H_{O}}{L_{O}}}}\right)
$$

Where $R_{\max }$ is the maximum wave run-up, $H_{o}$ is the deep water wave height, $\tan \beta$ is the beach slope and $\mathrm{L}_{\mathrm{o}}$ is the deep water wave length. $\mathrm{C}_{\text {perm }}$ is a non-dimensional permeability coefficient given by equation 10 ;

$$
c_{\text {perm }}=2.9737 k^{2}+1.6772 k+1.140
$$

Vousdoukas et al. [15] found that when introduced, wind and tidal elevations improved parameterization of wave run-up. Previous research has established that the performance of wave run-up models is influenced by the stage of the tide (e.g. Power et al. [16], Vousdoukas et al. [15]).

\section{METHODOLOGY}

\subsection{Study Area}

Research was carried out on three beaches in Trinidad namely Mayaro Bay, Cocos Bay and Grande Riviere Bay identified in figure 1 below. These beaches represent only a subset of the beaches for which comprehensive data collection will be carried out over the full duration of the research study. However, the selected beaches are able to provide insight into wave runup on local beaches that exhibit differing wave and beach characteristics.

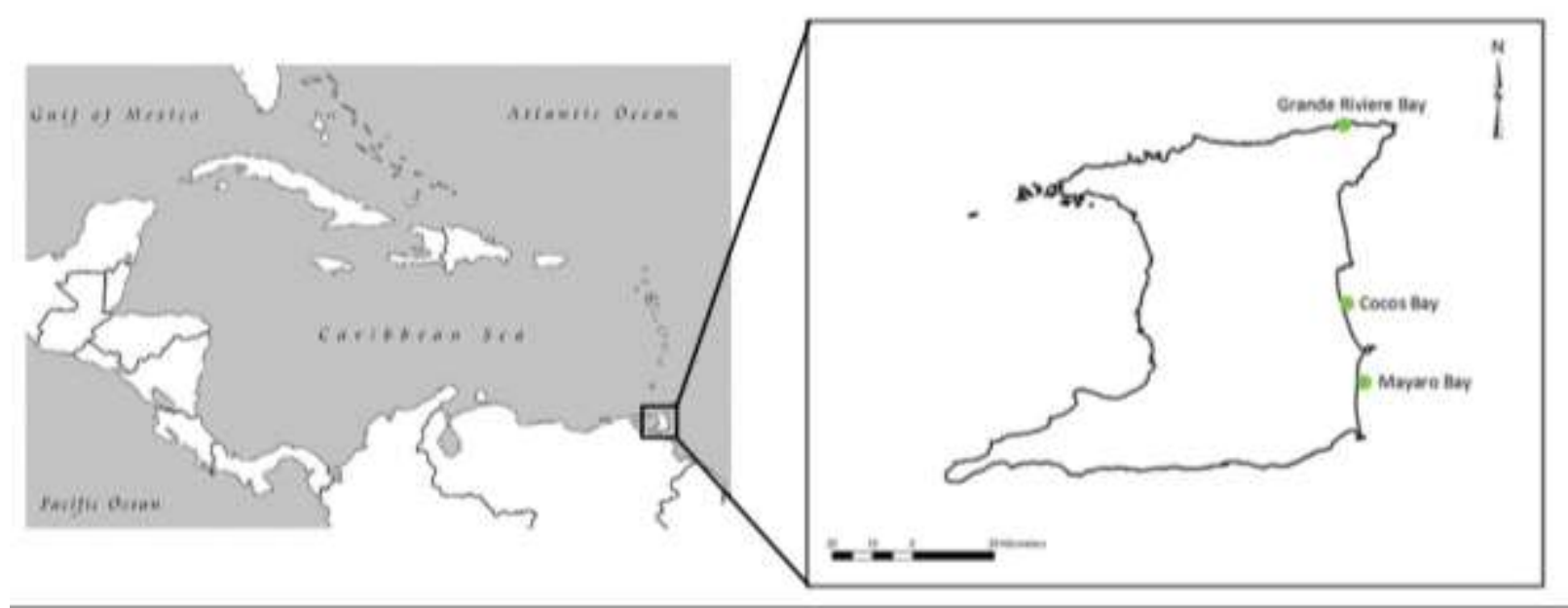

Figure 14 Map showing the location of the three field sites in Trinidad.

Cocos Bay and Mayaro Bay both located on the east coast of Trinidad are headland bay beaches approximately $21 \mathrm{~km}$ long. Cocos bay is a barrier beach that is backed by the Nariva Swamp [17]. 
Both are characterised micro-tidal conditions with mean significant wave heights of $0.48(+/-$ $0.12 \mathrm{~m})$ at Cocos Bay and $0.47 \mathrm{~m}(+/-0.16 \mathrm{~m})$ at Mayaro Bay [18]. At Cocos Bay the waves propagate from the east as rows of spilling breakers while at Mayaro Bay waves approach the bay from the east as high energy plunging or spilling breakers. The gently sloping beaches range from 7 to $11 \%$ in steepness [18]. The sediment consists primarily of fine grained, light brown sand and moderately sorted with mean grain sizes of $0.15 \mathrm{~mm}$ and $0.17 \mathrm{~mm}$ respectively.

Grande Riviere Bay is approximately $1.2 \mathrm{~km}$ long backed by a low plain of shrubs, vines, almond trees and coconut palms. The waves propagate from the north with high energy waves up to $2 \mathrm{~m}$ high in the dry season and up to $1 \mathrm{~m}$ in the wet season. The sediment consists of coarse-grained, light brown sand, primarily quarts and the foreshore beach slopes range from moderate to steep [19].

\subsection{Data collection and pre processing}

All runup data were collected through a combination of direct visual observation and total station surveying techniques. A cross shore transect was established from the berm to the safest position in the surf zone and marked by six (6) PVC pipes approximately $50 \mathrm{~cm}$ in length driven $20 \mathrm{~cm}$ into the bed. Immediately after each randomly selected swash event, the maximum runup positions in the line of the PVC pipes were visually observed and their positions and elevations surveyed with reference to WGS84 datum (default reference level in Trinidad). To reduce the effects of changing tide levels, the measurements were conducted at ten (10) minute intervals, every hour for one tidal cycle. The survey started one hour after low tide and ended one hour before high tide.

Traditional Surveying Techniques were also used to measure the elevations along the cross shore transect to define the foreshore beach slope. Following techniques by Guedes et al. [20], the foreshore beach was taken as the best linear fit of the measured beach surface between \pm two standard deviations from the mean run-up elevation for each data run. Elevations were measured approximately two (2) meters apart beginning at the berm and ending approximately one (1) $\mathrm{m}$ beyond the most likely lowest low tide swash elevation, along the cross-shore transect. All survey data was reduced to mean sea level using WGS 1984 Datum.

The deep water wave heights and periods were estimated using the MIKE21 Spectral Waves (SW) numerical model. The input wave conditions were obtained from the national Data Buoy centre located 470NM east of Martinique for each day of interest. Tide data was measured using a tide gauge deployed approximately two (2) m outside the breaker zone of the study area.

\subsection{Post-processing}

\subsubsection{Reducing Measurements to Mean Water Level (MWL)}

The run-up data collected is referenced to the World Geodetic System of 1984 (WGS 84) datum and therefore, it is necessary to correct the measured elevations to the MWL (or SWL), as proposed by Holman (1986). The MWL, referenced to the tidal elevations, is assumed to be the average of all water elevations collected for a period of 30 days. The difference in magnitude between the elevation of the mean sea level referenced to WGS84 and MWL relative to tide data is then applied to all run-up measurements. This difference is either subtracted from or added to 
the run-up measurements if the position of the datum is below or above the MWL established by the tide gauge respectively.

\subsubsection{Tide Corrections}

Individual run-up measurements are to be adjusted to account for the influence of changes in tide elevations. The tide data was collected for a maximum of one tidal cycle and changes in water level calculated as the difference between each measured water level elevation and the average over one cycle. Using a MATLAB script, the changes in water level were decomposed into waves, water levels and tide measurements. The decomposed changes in tide elevations were then added to the respective run-up elevations if measurements were taken during low tide and vice versa.

\subsection{Model Accuracy}

Using the four (4) run-up field data models outlined in section 2, predicted values of both the maximum run-up elevation, $R_{\max }$, and the run-up elevation exceeded by only $2 \%$ of swash events, $\mathrm{R}_{2} \%$, were calculated and compared to observed values of $\mathrm{R}_{\max }$ and $\mathrm{R}_{2} \%$. Five (5) statistical parameters were applied to assess the performance of each model: (1) Pearson's correlation coefficient ( $\mathrm{r}$ ) to determine the degree of the relationship between measured and predicted data (2) Coefficient of determination $\left(\mathrm{R}^{2}\right)$ to identify the percentage variance between variables and how well the data fits each model; (3) Root mean squared error (RMSE), (4) Bias to determine the absolute fit of each model to the data and (5) Scatter index (SI).

The Pearson's correlation coefficient (r) is estimated using the equation 11;

$$
r=\frac{n\left(\sum x y\right)-\left(\sum x\right)\left(\sum y\right)}{\sqrt{n\left(\sum x^{2}\right)-\left(\sum x\right)^{2}} \sqrt{n\left(\sum y^{2}\right)-\left(\sum y\right)^{2}}}
$$

Where $\boldsymbol{x}$ represents predicted run-up values and $y$ represents observed run-up values.

The mathematical formula for computing the Coefficient of determination $\left(\mathrm{R}^{2}\right)$ is presented in equation 12;

$$
R^{2}=\left(\frac{n \sum x y-\left(\sum x\right)\left(\sum y\right)}{\sqrt{n\left(\sum x^{2}\right)-\left(\sum x\right)^{2}} \sqrt{n\left(\sum y^{2}\right)-\left(\sum y\right)^{2}}}\right)^{2}
$$

Where $\boldsymbol{x}$ represents predicted run-up values and $y$ represents observed run-up values.

The goodness of fit of each predictor is then evaluated using the RMSE, bias analysis and SI. The RMSE is calculated using equation 13;

$$
\operatorname{RMSE}(x)=\sqrt{\frac{\sum_{i=1}^{N}\left(x_{\text {predicted }}-x_{\text {observed }}\right)^{2}}{n}}
$$


The equation 14 gives the bias estimator;

$$
\text { bias }(x)=\frac{1}{N} \sum_{i=1}^{N}\left(x_{\text {predicted }}-x_{\text {observed }}\right)
$$

The SI is calculated using equation 15 :

$$
S I=\frac{R M S E}{\sum_{i} x_{\text {observed } / N}}
$$

Low values of the RMSE and SI, values closer to zero (0), denotes better model performance. However, high values of $\mathrm{R}^{2}$, values closer to one (1) denotes better model performance. Positive and negative bias values indicate an overestimation and under-estimation of observed values respectively, whereas values equal to zero (0) demonstrates neither over nor under-estimation.

\section{4. $\quad$ Results}

A total of 474 individual run-up events were observed throughout the study on these three beaches with 99 run-up events measured at Grande Riviere, 172 run-up events measured at Mayaro and 203 run-up events observed at Manzanilla. A graph of predicted versus observed run-up elevations for $\mathrm{R}_{2} \%$ was plotted in figure 2 below. The black solid line represents where the measured and predicted values are equal to unity. Points that lie above that black line indicate an over prediction of values and vice versa. The dashed green lines represent a ten (10) percent error for both over and under prediction. A summary of the statistical analyses conducted is published in table 1 below. 


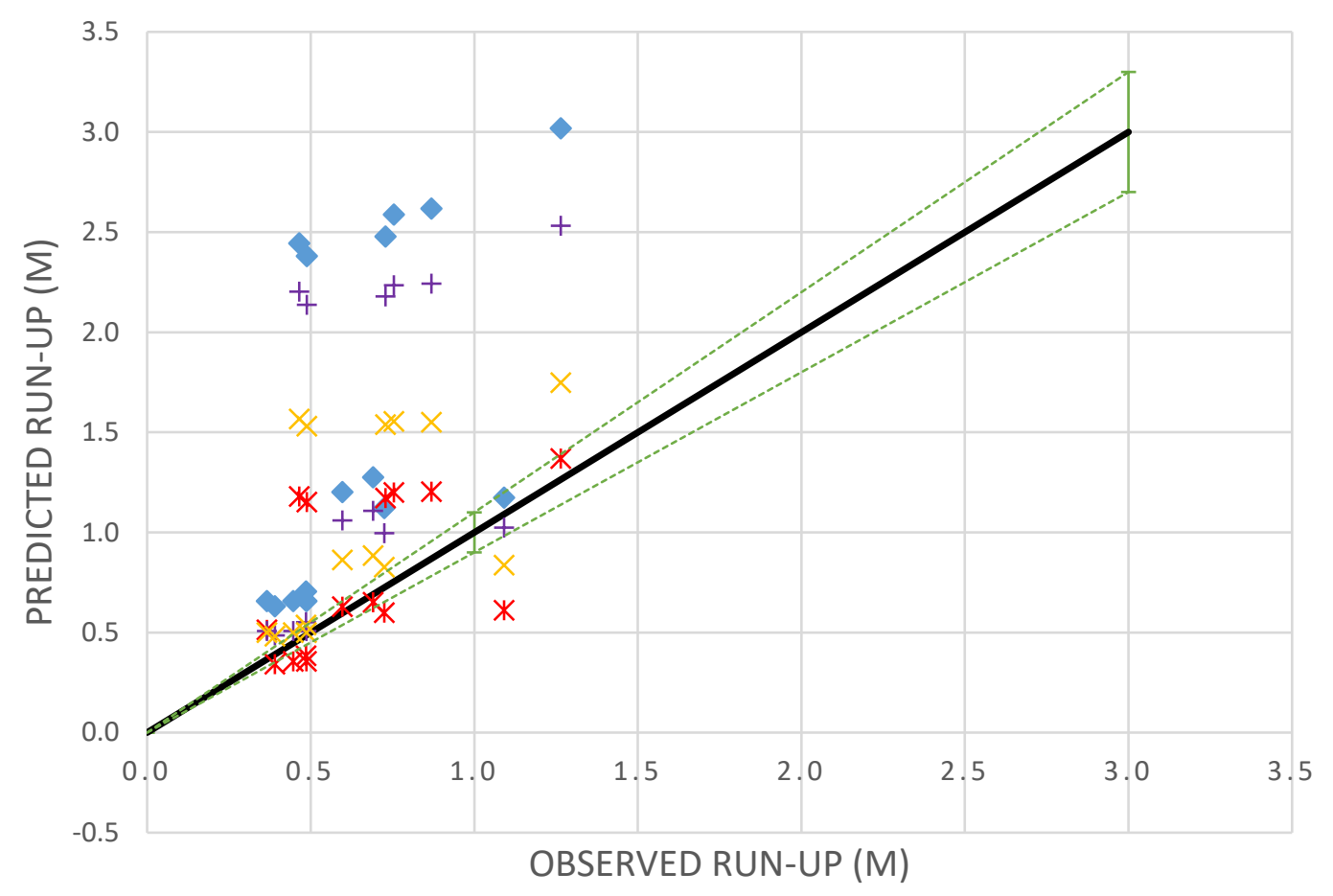

Nielsen and Hanslow (1991)

+ Holman (1986)
* Stockdon et al. (2006)

$\times$ Ruggiero et al. (2001)

Figure 15 - Graph illustrating predicted run-up elevations for the four models versus observed run-up elevations.

Table 7 Statistical error parameters obtained from the comparison among observed and predicted wave run-up elevations.

\begin{tabular}{|c|c|c|c|c|c|}
\hline Authors & $\mathrm{r}$ & $\mathrm{R}^{2}$ & RMSE & bias & SI \\
\hline Nielsen and Hanslow (1991) & 0.55 & 0.30 & 0.28 & 0.92 & 0.43 \\
\hline Ruggiero et al. (2001) & 0.53 & 0.28 & 0.19 & 0.02 & 0.29 \\
\hline Stockdon et al. (2006) & 0.52 & 0.27 & 0.15 & 0.01 & 0.15 \\
\hline Holman (1986) & 0.53 & 0.28 & 0.97 & 0.69 & 1.47 \\
\hline
\end{tabular}

From the graph in Figure 2, a positive correlation between all predictors and observed values of wave run-up is observed. This is further corroborated by the positive Pearson coefficients, $r$ presented in Table 1. However, the predictions of wave run-up generally did not show a good agreement with current run-up observations. Over prediction of run-up values increased as the 
observed run-up elevations increased in magnitude, starting at approximately $R_{2} \%=0.5$. This over prediction may be attributed to the lack of infiltration in the modelling of run-up equations. It can be considered that greater run-up values interact with a wider span of foreshore beach slope. In so doing, swash events are more likely to be affected by infiltration processes. Only seven (7) out of sixty (60) data points have an error of ten (10) percent, three of those belonging to Stockdon et al. [1]. This also corroborates the general poor performance of the selected equations to predict wave run-up.

Stockdon et al. [1] provides the best parameterization with a mean square error and SI of 0.15 followed by Ruggiero [2] with a RMSE 0.19 and SI of 0.29. The extensive data used to derive the equation by Stockdon et al. [1] may attribute to its performance above the other equations.

Other morpho-dynamic parameters such as friction and wind may also account for the over prediction of results. Theoretically, smoother slopes expect higher run-up values than rough slopes due to friction. In addition, tidal elevations were considered in this current data set but were omitted in the field study parameterizations of wave run-up under research, possibly contributing to the over prediction of run-up elevations.

Another possible factor responsible for the unfavourable predictions of wave run-up is the difference in methodologies conducted in the parameterizations of wave run-up by previous studies and the present research. While video derived data has its own limitations such as accurate detection of the leading edge and pixel resolution [15], the difference in sampling frequencies between the expressions under study and the current research may introduce errors. During the data collection process, it was purposed that the maximum point of run-up for each swash event within the time interval was observed. However, this was not allowed due to the time taken to capture elevations using the traditional surveying technique. The dynamic nature of the swash zone also did not allow for a consistent sampling frequency.

\section{Conclusion}

With the continued increase in sea level rise and resulting vulnerability of the coastal population, greater focus has been placed on the research of swash zone processes. More so, great effort has been placed on the accurate prediction of wave run-up over the last decade.

Observed values of run-up were compared to predicted measures of wave run-up by four (4) existing empirical formulae. An overprediction of wave run-up was predominantly observed in all equations at all study areas. This may be accounted for by the neglect of infiltration processes in their expressions. Equation by Stockdon et al. [1] performed the best with $\mathrm{RMSE}=0.15$ and $\mathrm{SI}=$ 0.15 . 


\section{References}

[1] Stockdon, H.F., et al., Empirical parameterization of setup, swash, and runup. Coastal Engineering, 2006. 53(7): p. 573-588.

[2] Ruggiero, P., Wave run-up on a high-energy dissipative beach. Journal of Geophysical Research, 2004. 109(C6).

[3] Senechal, N., et al., Wave runup during extreme storm conditions. Journal of Geophysical Research, 2011. 116(C7).

[4] Stockdon, H.F., et al., Evaluation of wave runup predictions from numerical and parametric models. Coastal Engineering, 2014. 92: p. 1-11.

[5] Van der Meer, J.W. and C.-J.M. Stam, Wave runup on smooth and rock slopes of coastal structures. Journal of Waterway, Port, Coastal, and Ocean Engineering, 1992. 118(5): p. 534-550.

[6] Pitman, S.J., Methods for field measurement and remote sensing of the swash zone. 2014.

[7] Vousdoukas, M.I., et al., Performance of intertidal topography video monitoring of a mesotidal reflective beach in South Portugal. Ocean Dynamics, 2011. 61(10): p. 1521-1540.

[8] Di Luccio, D., et al., Wave run-up prediction and observation in a micro-tidal beach. Natural Hazards and Earth System Sciences, 2018. 18(11): p. 2841.

[9] Silva, G.V.d., et al., Wave run-up on embayed beaches. Study case: Itapocorói Bay, Southern Brazil. Brazilian Journal of Oceanography, 2017. 65(2): p. 187-200.

[10] Hunt, I., Design of seawalls and breakwaters, US Corps Eng. Lake Surv. Detroit, 1959. 49.

[11] Miche, M., Le pouvoir réfléchissant des ouvrages maritimes exposés à l'action de la houle. Annales de Ponts et Chaussées, 121 (285-319), 1951.

[12] Nielsen, P. and D.J. Hanslow, Wave runup distributions on natural beaches. Journal of Coastal Research, 1991: p. 1139-1152.

[13] Holman, R., Extreme value statistics for wave run-up on a natural beach. Coastal Engineering, 1986. 9(6): p. 527-544.

[14] Villarroel-Lamb, D.A., A. Hammeken, and R. Simons, Quantifying the effect of bed permeability on maximum wave runup. Coastal Engineering Proceedings, 2014. 1(34): p. 45.

[15] Vousdoukas, M.I., D. Wziatek, and L.P. Almeida, Coastal vulnerability assessment based on video wave run-up observations at a mesotidal, steep-sloped beach. Ocean Dynamics, 2011. 62(1): p. 123-137.

[16] Power, H.E., R.A. Holman, and T.E. Baldock, Swash zone boundary conditions derived from optical remote sensing of swash zone flow patterns. Journal of Geophysical Research, 2011. 116(C6).

[17] Darsan, J., H. Asmath, and A. Jehu, Flood-risk mapping for storm surge and tsunami at Cocos Bay (Manzanilla), Trinidad. Journal of coastal conservation, 2013. 17(3): p. 679-689.

[18] Darsan, J., S. Ramnath, and C. Alexis, Status of beaches and bays in Trinidad 2004-2008. 2012, Technical Report Institute of Marine Affairs, Trinidad.

[19] Mycoo, M.A. and J.F. Gobin, Coastal management, climate change adaptation and sustainability in small coastal communities: leatherback turtles and beach loss. Sustainability science, 2013. 8(3): p. 441-453.

[20] Guedes, R.M.C., et al., The effects of tides on swash statistics on an intermediate beach. Journal of Geophysical Research: Oceans, 2011. 116(C4). 